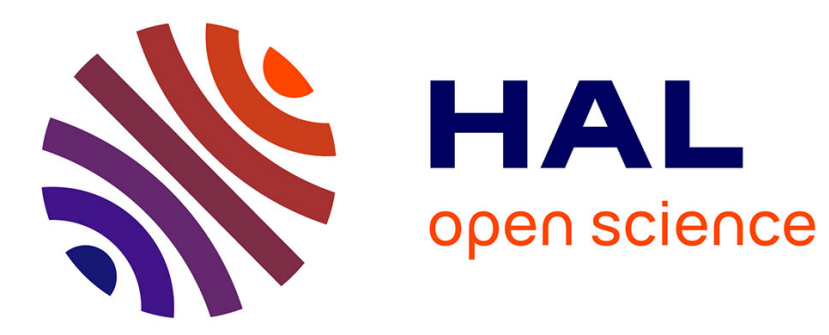

\title{
The first study on the impact of osmolytes in whole cells of high temperature-adapted microorganisms
}

Marta Salvador-Castell, Maksym Golub, Nicolas Martinez, Jacques Ollivier, Judith Peters, Philippe M. Oger

\section{- To cite this version:}

Marta Salvador-Castell, Maksym Golub, Nicolas Martinez, Jacques Ollivier, Judith Peters, et al.. The first study on the impact of osmolytes in whole cells of high temperature-adapted microorganisms. Soft Matter, 2019, 15 (41), pp.8381-8391. 10.1039/c9sm01196j . hal-02318499

\section{HAL Id: hal-02318499 \\ https://hal.science/hal-02318499}

Submitted on 9 Nov 2020

HAL is a multi-disciplinary open access archive for the deposit and dissemination of scientific research documents, whether they are published or not. The documents may come from teaching and research institutions in France or abroad, or from public or private research centers.
L'archive ouverte pluridisciplinaire HAL, est destinée au dépôt et à la diffusion de documents scientifiques de niveau recherche, publiés ou non, émanant des établissements d'enseignement et de recherche français ou étrangers, des laboratoires publics ou privés. 
archives-ouvertes

\section{The first study on the impact of osmolytes in whole cells of high temperature-adapted microorganisms}

Marta Salvador-Castell, Maksym Golub, Nicolas Martinez, Jacques Ollivier, Judith Peters, Philippe Oger

\section{To cite this version:}

Marta Salvador-Castell, Maksym Golub, Nicolas Martinez, Jacques Ollivier, Judith Peters, et al.. The first study on the impact of osmolytes in whole cells of high temperature-adapted microorganisms. Soft Matter, Royal Society of Chemistry, 2019, 15 (41), pp.8381-8391. 10.1039/c9sm01196j . hal02318499

\section{HAL Id: hal-02318499 \\ https://hal.archives-ouvertes.fr/hal-02318499}

Submitted on 9 Nov 2020

HAL is a multi-disciplinary open access archive for the deposit and dissemination of scientific research documents, whether they are published or not. The documents may come from teaching and research institutions in France or abroad, or from public or private research centers.
L'archive ouverte pluridisciplinaire HAL, est destinée au dépôt et à la diffusion de documents scientifiques de niveau recherche, publiés ou non, émanant des établissements d'enseignement et de recherche français ou étrangers, des laboratoires publics ou privés. 


\title{
ARTICLE
}

\section{The first study on the impact of osmolytes in whole cells of high temperature-adapted microorganisms}

Received 00th January 20xx, Accepted 00th January 20xx DOI: $10.1039 / x 0 x x 00000 x$

\author{
Marta Salvador Castell ${ }^{a}$, Maksym Golub ${ }^{b, c}$, Nicolas Martinez ${ }^{b, c}$, Jacques Ollivier ${ }^{c}$, Judith Peters ${ }^{c, d, *}$ \\ and Philippe Oger ${ }^{\mathrm{a}, *}$
}

\begin{abstract}
The hyperthermophilic piezophile Thermococcus barophilus displays a strong stress response characterized by the accumulation of the organic osmolyte mannosylglycerate during growth under sub-optimal pressure conditions ( $0.1 \mathrm{MPa}$ ). Taking advantage of this known effect, the impact of osmolytes in piezophiles in an otherwise identical cellular context was investigated, by comparing $T$. barophilus cells grown under low or optimal pressures (40 MPa). Using neutron scattering techniques, we studied the molecular dynamics of live cells of $T$. barophilus at different pressures and temperatures. We show that in presence of osmolytes, cells present a higher diffusion coefficient of hydration water and an increase of bulk water motions at high temperature. In absence of osmolytes, the $T$. barophilus cellular dynamics is more responsive to high temperature and high hydrostatic pressure. These results give therefore clear evidences for a protecting effect of osmolytes on proteins.
\end{abstract}

\section{Introduction}

Only few decades ago, it was thought that most extreme environments were too hostile to harbour life. However, since the major discoveries of the $1970 \mathrm{~s}^{1-3}$, it is admitted that possibly no place on Earth is too extreme to support cellular life. Indeed, nowadays, it is difficult to imagine limits for life on Earth and only one environmental condition seems limiting: the presence of liquid water. Amongst extreme biotopes, the most intriguing may be the deep-hot biosphere, where organisms experience high hydrostatic pressures (HHP) and high temperatures (HT) simultaneously. In this context, HHP refers arbitrarily to pressures above $10 \mathrm{MPa}$. It is among the prokaryotes (cells lacking a nucleus), and especially within the archaea domain that we find organisms adapted to the most extreme environmental conditions. The cellular adaptation to extreme conditions has been largely studied by different approaches from genomics, to protein and lipid studies ${ }^{4-7}$. It has allowed the identification of several adaptive routes that may, or may not be, shared between the different environmental stressors. For example, the sequence, and consequently the structure, of proteins is modified to respond to the specificities of some environment stressors (salinity, temperature) in order to maintain protein function and the molecular dynamics in the so-called "corresponding state principle" window ${ }^{8,9}$. Today, we are starting to understand the molecular basis of the structural and genetic adaptation to high temperature in protein of thermophiles. This implies the substitution of a set of preferred amino-acids in the sequence of the proteins. However, extensive whole genome studies were unsuccessfull to identify the structural and genetic adaptation to extreme pressure to date.

Recently, we have proposed the first molecular model for the adaptation to HHP in the archaeal order of the Thermococcales. Thermococcales are hyperthermophiles isolated from hydrothermal vent systems that can be found from the surface to the deepest part of the oceans ( $4500 \mathrm{~m}$ below sea level) and grow optimally at temperatures ranging from 75 to $105^{\circ} \mathrm{C}$. In our study, we compared Thermococcus kodakarensis, a piezosensitive (sensitive to HHP) archaeon to Thermococcus barophilus, a piezophile (requiring HHP for life) model species 10. Although pangenomic studies have failed to identify the genetic basis of the structural adaptation to HHP in these organisms, using incoherent neutron scattering on whole cells, we could demonstrate that the structural proteome adaptation to HHP occurs through variations of molecular dynamics in the proteome and in the hydration shell ${ }^{10}$. In contrast to the Le Chatellier principle ${ }^{11}$, it is expected that high pressure adapted

\footnotetext{
a. Address here.

b. Address here.

c. Address here.

† Footnotes relating to the title and/or authors should appear here.

Electronic Supplementary Information (ESI) available: [details of any supplementary information available should be included here]. See DOI: 10.1039/x0xx00000x
} 
proteins will resist increasing pressure better than piezosensitive ones to preserve the required protein flexibility of the active site. However, we found that proteins from the piezophile $T$. barophilus have a higher pressure sensitivity, undergo a phase-like transition with increasing pressure to reach their functional state and have a lower hydration shell contribution and dynamics. Furthermore, in contrast as well with expectations from high pressure studies, we showed that piezophilic cells perceive sub-optimal pressures as a stress, and counteract the effect of low-pressure stress by accumulating the organic osmolyte, mannosylglycerate (MG) ${ }^{12}$. To maintain the appropriate cell turgor and to restore the cell volume, all organisms accumulate low-molecular-weight osmolytes that are mainly organic solutes in response to cold, heat, $\mathrm{pH}$ and $\mathrm{HHP}$ stresses ${ }^{13}$. These solutes are amino acids and derivatives, polyols, sugars and derivatives, methylamines, and methylsulfonium compounds, which fall into only a few chemical categories: amino acids and derivatives such as trimethylamine oxide (TMAO) and small carbohydrates such as sugars, sugar derivatives, polyols and cyclitols 14-16. Some solutes, such as betaine, are widespread. To date, MG has only been detected in organisms thriving in hot environments ${ }^{15}$. Due to their stronger interaction with water than with macromolecules, many of these osmolytes help to stabilize macromolecular structures by enhancing water structure ${ }^{13}$. Therefore, they are accumulated to counteract the destabilizing effects of environmental stresses on cell components 15,17 . Although the mechanisms by which osmolytes help stabilize the proteome under low pressure stress in $T$. barophilus have not been explored yet, it is reasonable to assume that they will act as previously shown for other stresses, and in this particular case, as has been shown for MG, e.g. by rigidifying the macromolecular structures 18,19 .

Since most investigations only consider parts of cells separately 20-24, important effects resulting from the interplay of the different molecules or the crowding of the cellular milieu influencing the adaptation mechanisms might be overseen. Crowding is defined as the exclusion of volume by other polymers or the same polymer (self-crowding), which induces attraction between molecules caused by the lack of free space surrounding them. It is therefore a characteristic of concentrated solutions, such as a biological cell. Crowding and osmolytes are now recognized as important parameters of protein stability ${ }^{16,25}$. In the case of piezophiles, it is therefore crucial to determine their role in stress response and HHP adaptation. To reproduce these intracellular conditions, one can either employ self-crowding, which allows to reproduce the high cytoplasmic protein concentrations (around $300 \mathrm{mg} / \mathrm{mL}^{26}$, $\left.{ }^{18}\right)$, but fails at capturing the diversity and complexity of proteins present; or use crowding agents such as osmolytes, which simulate well the interaction with water molecules but also fail at simulating the complexity of intracellular media. Despite these limitations, several studies have demonstrated the protecting effect of osmolytes and crowding on the HHP tolerance of proteins in vitro 25,27 . To extend and confirm this data in a meaningful context, a whole cell approach has been designed to provide a third alternative for studying the effect of

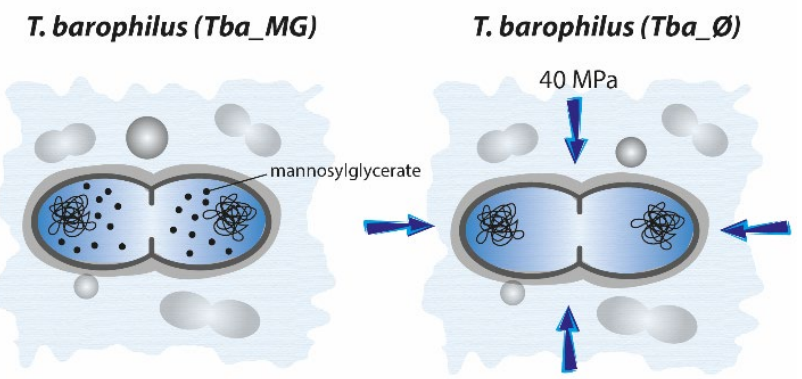

Figure 1. Schematic representation of differences between the two samples of $T$. barophilus, used in this study. Tba_ $\varnothing$ (right) is grown under optimal pressure and temperature conditions. Tba_MG (left) is grown at optimal temperature but atmospheric pressure. Since atmospheric pressure is perceived as a stress by $T$. barophilus, it will accumulate significant levels of mannosylglycerate, an organic osmolyte, to maintain the functionality of cellular macromolecules.

high concentrations in a realistic biological context 10,28-33. These studies use neutron scattering to determine the dynamics inside the cells, which is the method of choice because as it does not induce radiation damage to cells while it allows to separate the molecular dynamics of cell constituents or water directly inside in vivo cells ${ }^{34}$. In contrast to studies on the impact of crowding on pure proteins, cell studies showed that the release of crowding constraints on proteins leads to an increase in rigidity and a decrease in HHP sensitivity. In a way similar to HHP adaptation in piezophiles, the hydration water layer is decreased when crowding is decreased 35, demonstrating a first link between protein adaptation and the impact of crowding or osmolytes on proteins.

In the experimental setup of the Golub study ${ }^{35}$, the variations in crowding were generated by cell lysis. In the present study, we take advantage of the accumulation of osmolytes by the piezophilic archaeon $T$. barophilus under low pressure stress 12 in order to test the impact of the presence of osmolytes in a relevant cellular context (Figure 1).

\section{Experimental section}

\section{Sample preparation}

Cell samples were prepared for neutron scattering immediately before the start of beam-time. Cells of $T$. barophilus were cultivated in 4 litres of Thermococcales' rich medium ${ }^{36}$, under anoxic conditions at $358 \mathrm{~K}$ until late exponential phase. The first sample (Tba_ $\varnothing$ ) was grown under optimal conditions, e.g. at 40 $\mathrm{MPa}$ in Poly Ethylene Terephthalate (PET) bags. Under these culture conditions, $T$. barophilus cells do not accumulate osmolytes. The second sample (Tba_MG) was cultivated under low-pressure stress, e.g. at atmospheric pressure. Under these culture conditions, cells are known to accumulate MG ${ }^{37}$. Cells were concentrated by centrifugation at $14000 \mathrm{~g}$ for $30 \mathrm{mn}$, and washed twice with saline solution. To avoid possible damage to the cell during sample preparation for the high pressure cell, all manipulations were performed at $4^{\circ} \mathrm{C}$, a temperature which blocks all metabolic activity in Thermococcus cells, and increases their tolerance to oxygen. Thus, both samples were constituted of live $T$. barophilus cells. Samples were kept under anoxic atmosphere. For neutron experiments, about $600 \mathrm{mg}$ of cell pellets were transferred under anoxic atmosphere as 
described previously ${ }^{10}$ to the HP cell sample insert ${ }^{38}$. In brief, the cell pellet was transferred to the insert using a syringe and a blunted $0.9 \mathrm{~mm}$ needle and deposited at the bottom of the sample holder to avoid the formation of gas bubbles. The sample geometry in this insert is $10 \mathrm{~mm} \times 59 \mathrm{~mm}$ and $1 \mathrm{~mm}$ thickness. The residual space was filled with $2.5 \% \mathrm{NaCl}$ saline solution in $\mathrm{D}_{2} \mathrm{O}$ to guarantee a homogeneous pressure transmission. A cryostat was used to precisely control and change the temperature. The HHP transmitting medium in the heated HHP stick was Fluorinert ${ }^{39}$ which is completely inert and which was separated from the sample by a HHP separator 40 . Neutron data is acquired on live cells. Under the conditions used for data acquisition (see details below), cells remain alive, but are metabolically inactive below $343 \mathrm{~K}$. At the highest temperature tested, $358 \mathrm{~K}$, cells are potentially active but in absence of a suitable carbon source, no activity was detected in the lab, and thus no metabolic activity should occur within the HP cell. Cell survival was estimated by microscopic observation of the fraction of lyzed cells, as a proxy for cell survival. No significant viability decrease was observed at the end of experiments. This is similar to previous experimentation 10 showing that there is no loss of viability during irradiation, and that samples are indistinguishable in terms of molecular dynamics before and after data acquisition.

\section{Incoherent neutron scattering}

Atomic nuclei scatter neutrons coherently and incoherently, but the incoherent part, which refers to molecular dynamics, is the significant contribution when using disordered samples ${ }^{34}$ as it is the case for entire cells in solution. For the hydrogen $\left({ }^{1} \mathrm{H}\right)$, the incoherent scattering cross section is much larger than for any other atomic nucleus present in biological samples ${ }^{41}$, therefore, the use of neutrons to be diffused on entire cells allows to determine the average motions of the hydrogens and the molecular subgroups bound to them. We used elastic incoherent neutron scattering (EINS) on the backscattering spectrometer IN13 42 and quasi-elastic neutron scattering (QENS) on the time-of-flight spectrometer IN5 ${ }^{43}$ at the Institut Laue Langevin (ILL, France).

In addition to the cell pellets, we have measured the buffer, i.e. $\mathrm{D}_{2} \mathrm{O}$ added as a pressure transmitter to the HHP cell, for a later subtraction from the sample signal, and a vanadium rod, which scatters purely incoherently and is used to mimic the instrumental energy resolution. The data reduction was carried out using the Large Array Manipulation Program (LAMP) available at ILL ${ }^{44}$ and Origin (http://www.originlab.com/).

Possible multiple scattering effects for a sample in a similar HHP sample container were evaluated previously and we have found that this effect was significant only at very low $Q$-values ${ }^{45}$. This result is also in agreement with findings by $\mathrm{S}$. Busch and $\mathrm{T}$. Unruh ${ }^{46}$.

\section{Elastic incoherent neutron scattering}

The elastic contribution refers to an energy transfer between the neutron and the scatterer equal to zero when hydrogens perform only atomic vibrations around their equilibrium positions. The incident wavelength on IN $133^{42}$ of $2.23 \AA$ gives an almost momentum transfer independent energy resolution of 8 $\mu \mathrm{eV}$. IN13 is characterized by a very large momentum transfer range $\left(0.2 \AA^{-1}<Q<4.9 \AA^{-1}\right.$, where $Q$ is the difference between the incoming and outgoing neutron wave vector) that corresponds to a space and time window of 1-30 $\AA$ and 100 ps, respectively. To determine their dynamics at extreme conditions, we have measured both samples at different temperatures $(298 \mathrm{~K}, 312 \mathrm{~K}, 326 \mathrm{~K}, 345 \mathrm{~K}$ and $358 \mathrm{~K})$ and pressures (0.1 MPa, 20 MPa, $30 \mathrm{MPa}$ and $40 \mathrm{MPa}$ ). Due to the high thermal inertia of the HHP cell, temperature was increased from the lowest to the highest, and data acquisition at each pressure was performed during the temperature plateau. Each data point lasted from $1.5 \mathrm{~h}$ at $298 \mathrm{~K}$ to $4.5 \mathrm{~h}$ at $358 \mathrm{~K}$, for a total acquisition time including HHP and T ramps of $48 \mathrm{~h}$ per sample. $\mathrm{P}$ ramps were of $3 \mathrm{MPa}$ per minute. T ramps were of $0.5^{\circ} \mathrm{C}$ per minute.

The elastic structure factor is given within the Gaussian approximation (Equation 1) 47,48:

$S_{e l}(Q, 0 \pm \Delta E) \approx S_{0} \exp \left(\frac{-1}{3}<u^{2}>Q^{2}\right)$

where $\Delta E$ is the half-width half maximum (HWHM) of the instrumental energy resolution; $\left\langle u^{2}\right\rangle$ is the atomic mean square displacement (MSD). The MSD indicates the flexibility of the sample under specific conditions of pressure and temperature. The MSD can be obtained for each temperature or pressure value by the slope of the semi-logarithmic plot of the incoherent scattering function through equation 2 :

$u^{2}>\approx-3 \frac{d \ln S_{e l}(Q, 0 \pm \Delta E)}{d Q^{2}}$

Equation 2 is valid for small Q-values, when $\left\langle u^{2}>Q^{2} \sim 1\right.$. Accordingly, we restricted the fit range to the $Q$ regime between 0.19 and $1.47 \AA^{-1}$. The MSD is inversely proportional to the sum over the scattering intensities (summed I), however, the summed I does not require the Gaussian approximation and a broader Q-range can be used, which increases statistics.

\section{Quasi-elastic neutron scattering}

The QENS part of the incoherent neutron scattering appears as a broadening of the elastic peak resulting from the relaxation of atomic motions in the spatial and temporal windows of the instrument. QENS reveals the scattering that presents an exchange of small amounts of energy between the neutrons and the sample ${ }^{34}$.

The incoming wavelength on IN5 ${ }^{43}$ was $10 \AA$, which amounts to an instrumental energy resolution of $10 \mu \mathrm{eV}$ and a momentum 

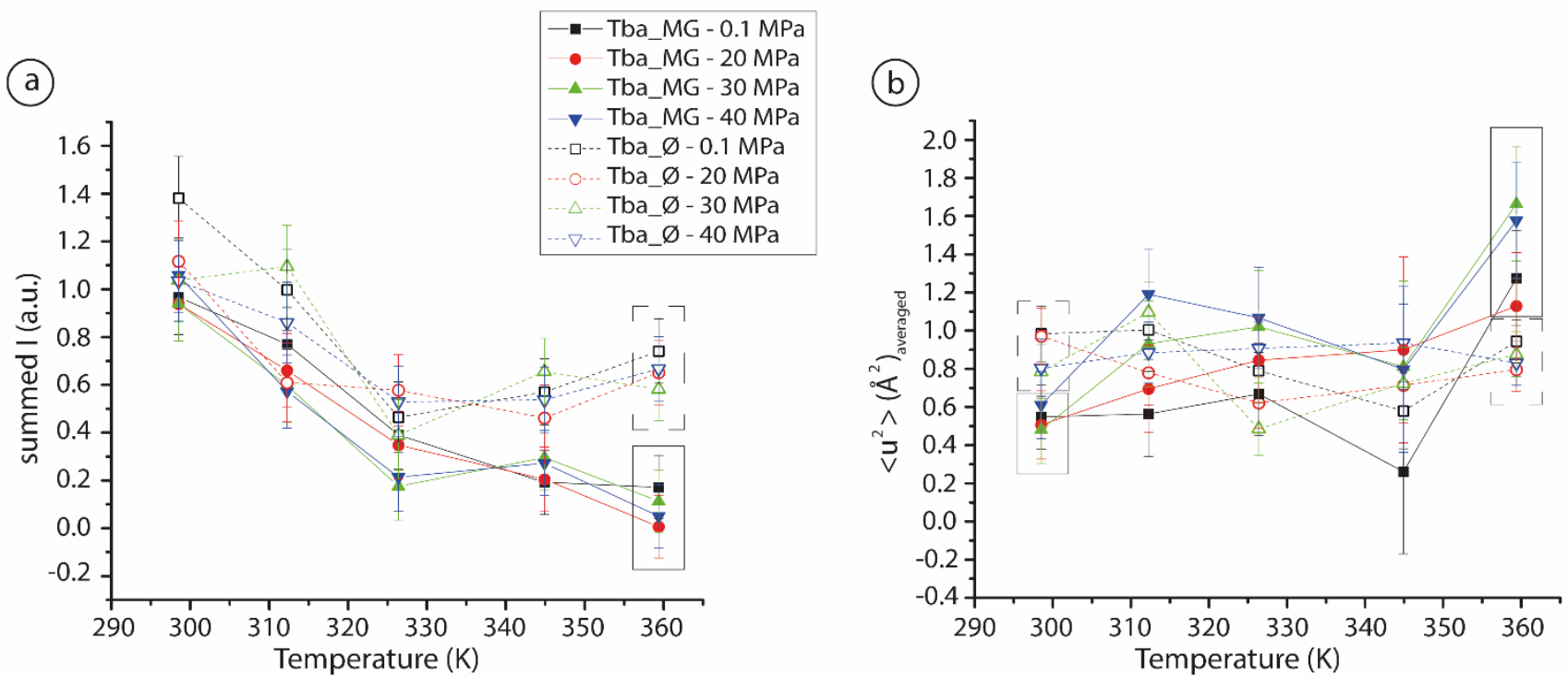

Figure 2. Summed Intensities (A) and MSD <u2> (B) plotted against temperature for Tba_MG (filled symbols) and Tba_ $\varnothing$ (empty symbols) at different pressures (0.1 MPa (black squares), $20 \mathrm{MPa}$ (red circles), $30 \mathrm{MPa}$ (green point up triangles) and $40 \mathrm{MPa}$ (blue point down triangles).

transfer range of about $0.2<Q<1.1 \AA^{-1}$. Such setup permits to probe internal local movements with a space-time window of up to $32 \AA$ and 100 ps, respectively. With samples such as whole live cells, a more thorough data analysis of water behaviour has proven impossible, due to the resolution of the instrument and the complexity of the samples. The Q-range used here has been shown previously to be the best compromise to obtain the parameters of the molecular dynamics of whole cells 10,35 . Samples were measured for $30 \mathrm{mn}$ per data point at two temperatures ( $298 \mathrm{~K}$ and $358 \mathrm{~K}$ ) and two pressures (0.1 MPa and $40 \mathrm{MPa})$.

In QENS data, a diffusional motion can be described by a Lorentzian curve. As more than one molecular population is present here and each contributes differently to the total scattering intensity, the experimental curve scattered by cells can be fitted by a sum of Lorentzian functions ${ }^{34}$. In theory, the sum could go over an infinity of Lorentzian curves, as there exists infinity multitude of dynamical populations (e.g. from water molecules, biomolecules and co-solutes) and many possible models were suggested in the past how to treat best QENS data of complex systems ${ }^{20-24,49}$. However, in practice, the precision of our data does not permit to distinguish more than a few contributions in the instrumental resolution window represented by individual Lorentzian curves, which allows to restrict the sum and to extract characteristic parameters for some specific detected populations. Here, we use the model presented by Martinez et al. ${ }^{10}$ for the same type of samples. Therefore, we can split the signal into four different contributions: an elastic peak, one Lorentzian function corresponding to the proteome, one to the hydration water and one to the bulk water contribution and a constant background $B(Q)$. All functions are convolved by the instrumental resolution function $S_{\text {resolution }}(Q, \omega)$ (Equation 3 ):

$S(Q, \omega) \approx\left[p_{\text {elastic }}+p_{\text {bulk }} \times S_{1}\left(Q, \omega, D_{\text {Tbulk }}, \tau_{\text {bulk }}\right)+\right.$ $p_{\text {hydration }} \times S_{2}\left(Q, \omega, D_{\text {Thydration }}\right)+p_{\text {proteome }} \times$

$\left.S_{3}\left(Q, \omega, \Gamma_{\text {proteome }}\right)\right] \otimes S_{\text {resolution }}(Q, \omega)$ where $S_{1}(Q, \omega)$ and $S_{2}(Q, \omega)$ are the structure factors 34 corresponding to the contributions of bulk and hydration water, respectively. These two components are characterized by a translational diffusion constant $D_{T}$, a rotational diffusion constant $D_{R}$ and a residence time $\tau{ }^{50}$, which describes the typical time a water molecule performs oscillatory motions around its equilibrium position before diffusing continuously.

The contribution $\mathrm{S}_{3}$ is associated with all possible motions within the biological system itself (the proteome) and presents a faster relaxation which is described by a large Lorentzian with a constant HWHM ( $\left.\Gamma_{\text {proteome }}\right)^{10}$. The p-values represent the fractions of each contribution: elastic, bulk water, hydration water and proteome. The sum of all populations is equal to one, with around $70-80 \%$ of total water content ${ }^{49,51}$.

The two water populations were fitted by a convolution of two Lorentzians representing the translational diffusion and rotational diffusion that occur simultaneously. However, the rotational diffusion was small and constant for all samples ${ }^{10,35}$, so we neglected it. Finally, $\tau$ can be determined when HWHM tends to a constant value at high Q-values. The Q-range of IN5 did not allow to reach such high Q-values for the hydration water population and, therefore, it was not determined. We normalized each spectrum to unity in its maximum to neglect the Debye-Waller-factor, which does not introduce additional information for QENS analysis.

\section{Results and discussion}

Experiments were performed in December 2015 on IN13 (DOI: 10.5291/ILL - Data.8-04-763) and in November 2016 on IN5 (DOI: 10.5291/ILL - Data.8-04-783), therefore separate sets of samples were produced. The results established the reproducibility of the outcome from various samples. 


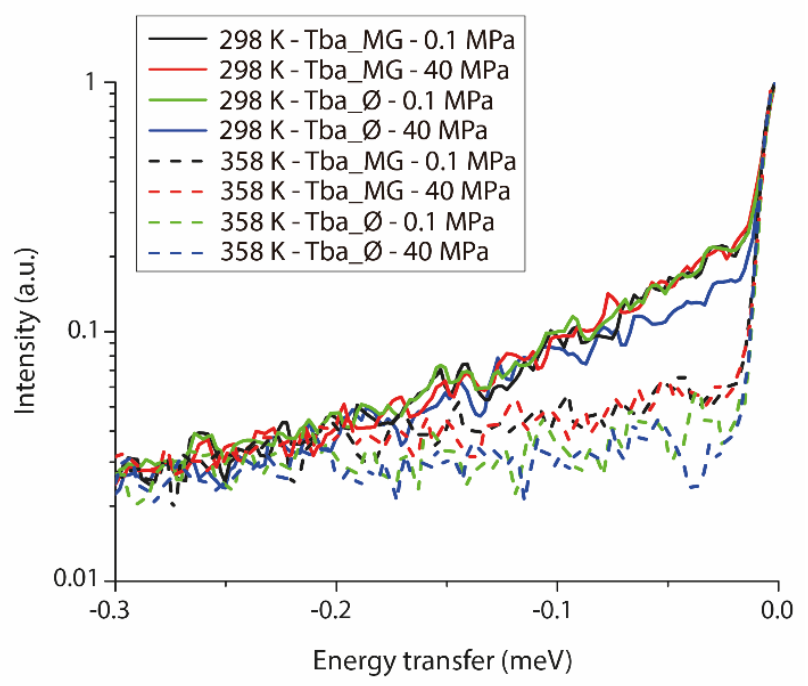

Figure 3. Normalized QENS spectra of whole Tba_MG and Tba_ $\varnothing$ cells at $298 \mathrm{~K}$ (solid lines), $358 \mathrm{~K}$ (dash lines) and $0.1 \mathrm{MPa}$ or $40 \mathrm{MPa}$ at $\mathrm{Q}=0.87 \AA-1$ on a semilogarithmic scale. The figure highlights significant divergence in dynamics between the samples visible in the low energy region.

\section{EINS}

The samples were measured by EINS on IN13 at temperature and pressure values within the physiological range for the cells, i.e. between 0.1 and $40 \mathrm{MPa}$ and between 293 and $358 \mathrm{~K}$. Intensities were summed over all scattering angles, while the MSD were extracted in a restricted $Q$ range between 0.19 and $1.47 \AA^{-1}$. Summed I and MSD, according to equation (2), are presented in Figure $2 a$ and $2 b$, respectively. As observed in previous experiments using the high-pressure cell, the signal is somewhat noisy due to the high neutron absorption, but significant differences can be observed between the two sample types.

Some differences in summed intensities between the probed systems are identified in temperature-dependent comparisons (Figure 2), but no difference is observed within the pressure range studied here (Figure S1 \& S2). Up to $325 \mathrm{~K}$, the summed I decrease for both samples with increasing temperature (Figure 2a), and the dynamics of both systems increase as expected from a temperature increase (Figure $2 b$ ). The curves of both samples display two different regimes with a change of slope at ca. $325 \mathrm{~K}$. For Tba_ $\varnothing$, the sample grown at optimal conditions, the summed I increase slightly above $325 \mathrm{~K}$, indicating that cell molecular dynamics are stabilized when cells are approaching their optimal growth temperature $(358 \mathrm{~K})$. In contrast, for the sample grown under pressure stress (Tba_MG) which accumulates mannosylglycerate, the summed I further decreases (the MSD increases) but at a lower rate. This change in cell dynamics is indicative of structural rearrangements of the cell's macromolecules, which in the current setup correspond mostly to proteins. It is noteworthy that such structural rearrangements have been previously reported for the $T$. barophilus proteome between low and optimal hydrostatic pressures ${ }^{52}$, and proposed to be part of the HHP adaptation in this species. Interestingly, the critical temperature found here (325 K) is very close to the minimal growth temperature of $T$. barophilus $(321 \mathrm{~K}){ }^{53}$ which further substantiates a possible

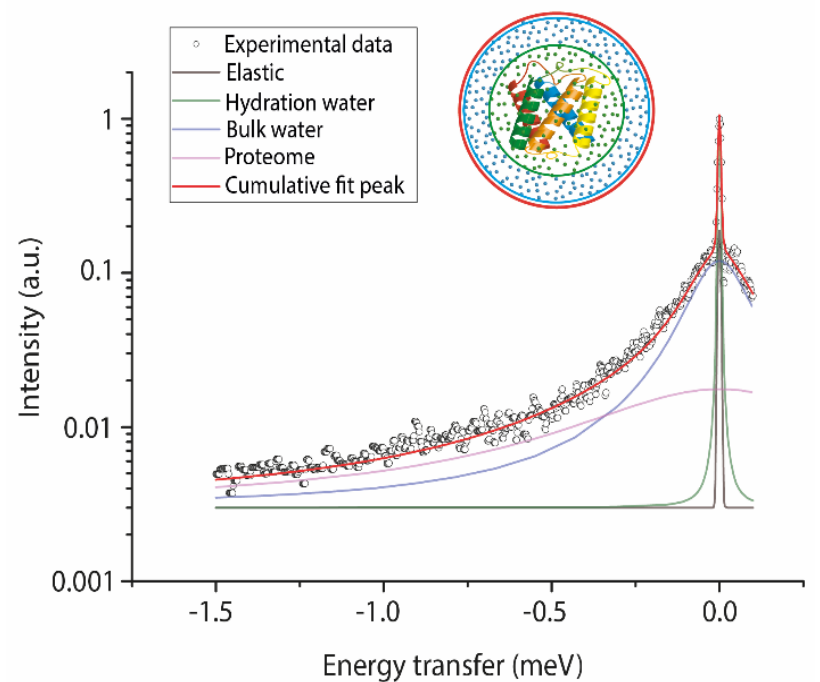

Figure 4. Normalized QENS spectra and fit for Tba_ $\varnothing$ at $298 \mathrm{~K}, 40 \mathrm{MPa}$ and Q $=0.96$ $\AA-1$ on a semi-logarithmic scale. Scheme in the red circle represents the different populations studied, the ribbons represent a protein and the dots water molecules (green for hydration water and blue for bulk water).

physiological requirement for the $T$. barophilus proteome as proposed earlier 12,52. All these findings suggest that the proteome of this species is in a destabilized, partially nonfunctional form at temperatures below $321 \mathrm{~K}$, which might explain its inability to grow below that temperature, and that this organism gets into functional intracellular dynamics only at ca. $321 \mathrm{~K}$. Similarly to what has been observed for HHP ${ }^{52}$, once the functional dynamics is achieved, the cell dynamics becomes insensitive to further increase in temperature probably up to its maximum growth temperature $(373 \mathrm{~K}){ }^{53}$. The presence of MG in sample Tba_MG seems to inhibit the extent of the structural rearrangements of the proteome, which is expected if MG rigidifies and stabilizes the proteome. The MSD confirms the

\begin{tabular}{|c|c|c|c|c|}
\hline \multirow{2}{*}{$298 \mathrm{~K}$} & \multicolumn{2}{|c|}{ Tba_MG } & \multicolumn{2}{|c|}{ Tba_ø } \\
\hline & $0.1 \mathrm{MPa}$ & $40 \mathrm{MPa}$ & $0.1 \mathrm{MPa}$ & $40 \mathrm{MPa}$ \\
\hline$P_{\text {elastic }}$ & $0.01 \pm 0.01$ & $0.01 \pm 0.01$ & $0.01 \pm 0.01$ & $0.01 \pm 0.01$ \\
\hline$P_{\text {hydration }}$ & $0.11 \pm 0.02$ & $0.11 \pm 0.02$ & $0.10 \pm 0.02$ & $0.11 \pm 0.02$ \\
\hline$P_{\text {bulk }}$ & $0.65 \pm 0.03$ & $0.65 \pm 0.03$ & $0.66 \pm 0.03$ & $0.65 \pm 0.03$ \\
\hline$P_{\text {proteome }}$ & $0.25 \pm 0.03$ & $0.25 \pm 0.03$ & $0.24 \pm 0.03$ & $0.25 \pm 0.03$ \\
\hline$D_{\text {Tbulk }}\left(10^{-5} \mathrm{~cm}^{2} / \mathrm{s}\right)$ & $1.85 \pm 0.05$ & $1.85 \pm 0.05$ & $1.85 \pm 0.05$ & $1.85 \pm 0.05$ \\
\hline$\tau_{\text {Tbulk }}(\mathrm{ps})$ & $0.91 \pm 0.10$ & $1.64 \pm 0.07$ & $0.96 \pm 0.09$ & $1.45 \pm 0.11$ \\
\hline$D_{\text {Thydration }}\left(10^{-7} \mathrm{~cm}^{2} / \mathrm{s}\right)$ & $5.9 \pm 0.3$ & $4.5 \pm 0.3$ & $5.7 \pm 0.3$ & $2.9 \pm 0.3$ \\
\hline$\Gamma_{\text {proteome }}(\mathrm{meV})$ & $0.43 \pm 0.01$ & $0.43 \pm 0.01$ & $0.43 \pm 0.01$ & $0.43 \pm 0.01$ \\
\hline
\end{tabular}

\begin{tabular}{|c|c|c|c|c|}
\hline \multirow{2}{*}{$358 \mathrm{~K}$} & \multicolumn{2}{|c|}{ Tba_MG } & \multicolumn{2}{|c|}{ Tba_ø } \\
\hline & $0.1 \mathrm{MPa}$ & $40 \mathrm{MPa}$ & $0.1 \mathrm{MPa}$ & $40 \mathrm{MPa}$ \\
\hline$P_{\text {elastic }}$ & $0.01+0.01$ & $0.01+0.01$ & $0.01+0.01$ & $0.01+0.01$ \\
\hline$P_{\text {hydration }}$ & $0.22 \pm 0.03$ & $0.21 \pm 0.03$ & $0.21 \pm 0.03$ & $0.21 \pm 0.03$ \\
\hline$P_{b u l k}$ & $0.47 \pm 0.05$ & $0.47 \pm 0.05$ & $0.47 \pm 0.05$ & $0.46 \pm 0.05$ \\
\hline$P_{\text {proteome }}$ & $0.31 \pm 0.05$ & $0.32 \pm 0.05$ & $0.32 \pm 0.05$ & $0.33 \pm 0.05$ \\
\hline$D_{T h u l k}\left(10^{-5} \mathrm{~cm}^{2} / \mathrm{s}\right)$ & $5.2+0.1$ & $5.1+0.1$ & $6.7+0.1$ & $6.6+0.1$ \\
\hline$\tau_{\text {Tbulk }}(\mathrm{ps})$ & $0.10 \pm 0.05$ & $0.11 \pm 0.05$ & $0.46 \pm 0.09$ & $0.47 \pm 0.08$ \\
\hline$D_{\text {Thydration }}\left(10^{-7} \mathrm{~cm}^{2} / \mathrm{s}\right)$ & $5.6 \pm 0.4$ & $4.0 \pm 0.4$ & $2.7 \pm 0.4$ & $1.8 \pm 0.4$ \\
\hline$\Gamma_{\text {proteome }}(\mathrm{meV})$ & $0.61 \pm 0.01$ & $0.61 \pm 0.01$ & $0.61 \pm 0.01$ & $0.61 \pm 0.01$ \\
\hline
\end{tabular}

Table 1. Fit parameter values for the two samples at different pressures $(0.1 \mathrm{MPa}$ and $40 \mathrm{MPa}$ ) and temperatures (298 $\mathrm{K}$ and $358 \mathrm{~K}$ ). The fields in green show characteristic responses to HHP for piezophiles. Dark green indicates similarities between samples, light green fields point out parameters differing between samples. The fields in blue correspond to the osmolyte effect on bulk water. The fields in red are indicative of a different response to HT between samples. 
low overall dynamics sensitivity of Tba_ $\varnothing$ and the increase of the dynamics at higher temperatures for the Tba_MG sample (Figure 2b). As seen in the summed $\mathrm{I}$, the overall dynamics of Tba_ $\varnothing$ is more insensitive to temperature than that of Tba_MG.

\section{QENS}

QENS data were acquired at two temperatures, $298 \mathrm{~K}$ and 358 $\mathrm{K}$, and two pressures, 0.1 and $40 \mathrm{MPa}$ on IN5 at ILL. As expected, the intensities summed over all available scattering angles revealed important changes in dynamics due to temperature, and small changes due to pressure application for both samples (Figure 3). Smaller differences are visible in the low energy transfer region $(-0.2$ to $0 \mathrm{meV}$ ) in response to HHP (Tba_ $\varnothing$ at 0.1 $\mathrm{MPa}$ vs. Tba_ $\varnothing$ at $40 \mathrm{MPa})$ or the presence of mannosylglycerate (Tba_ $\varnothing$ vs. Tba_MG, at $358 \mathrm{~K}$ ) on molecular dynamics. The dynamical parameters that can be extracted from the QENS data all relate to translational or rotational diffusion and relaxation processes. The data was fitted according to the model of Martinez et al. 10 with four

(a)

\section{$298 \mathrm{~K}$}

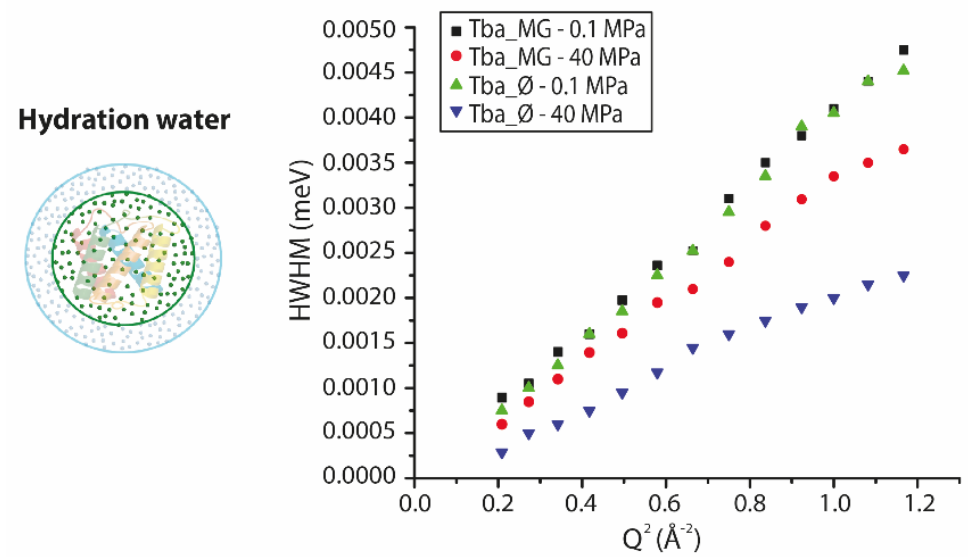

populations: elastic contribution ( $\left.p_{\text {elastic }}\right)$, bulk water ( $\left.p_{\text {bulk }}\right)$, hydration water $\left(p_{\text {hydration }}\right)$ and proteome $\left(p_{\text {proteome }}\right)$. It appeared to be the best compromise between the extraction of a minimum of valuable results to characterise the dynamics and the risk of overfitting the data by a too complex model. Each Lorentzian curve has its characteristic HWHM value as function of $Q$, which is directly related to each population dynamics. The best fit values along with errors obtained through error propagation are given in Table 1 , and an example of the experimental data compared with a fit is given in Figure 4 (for more examples, see Figure S3 - S10).

\section{Pressure and osmolyte accumulation effects on intracellular} dynamics at $298 \mathrm{~K}$. The relative contributions of the four populations for both samples ( $p_{\text {elastic }}, p_{\text {bulk }}, p_{\text {hydration, }}, p_{\text {proteome }}$ ) and the extracted motion parameters are of the same order as those determined before by Martinez et al. ${ }^{10}$ which are characteristic for a piezophile microorganism (Table 1$)$. $\Gamma_{\text {proteome }}(0.43 \pm 0.01$

Figure 5. HWHM of the translational hydration water (represented by green dots in the left scheme) for both samples at different pressure (0.1 MPa and $40 \mathrm{MPa}$ ) and temperature values (a) $298 \mathrm{~K}$ and b) $358 \mathrm{~K}$ ) as a function of Q2.

(b)

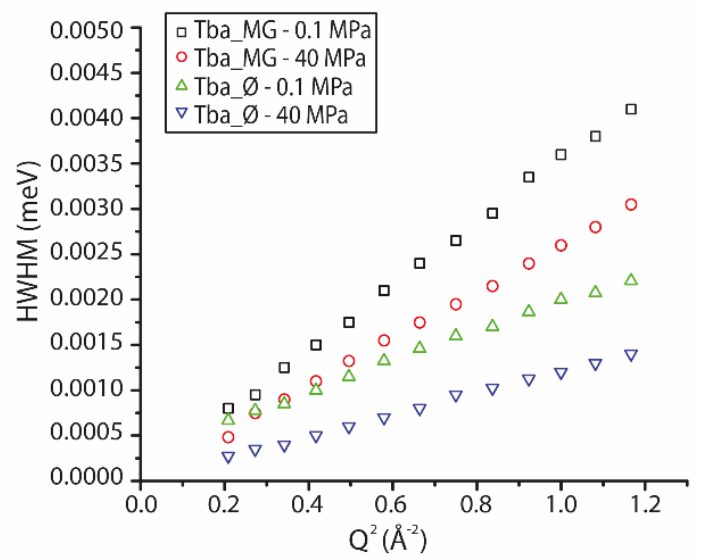

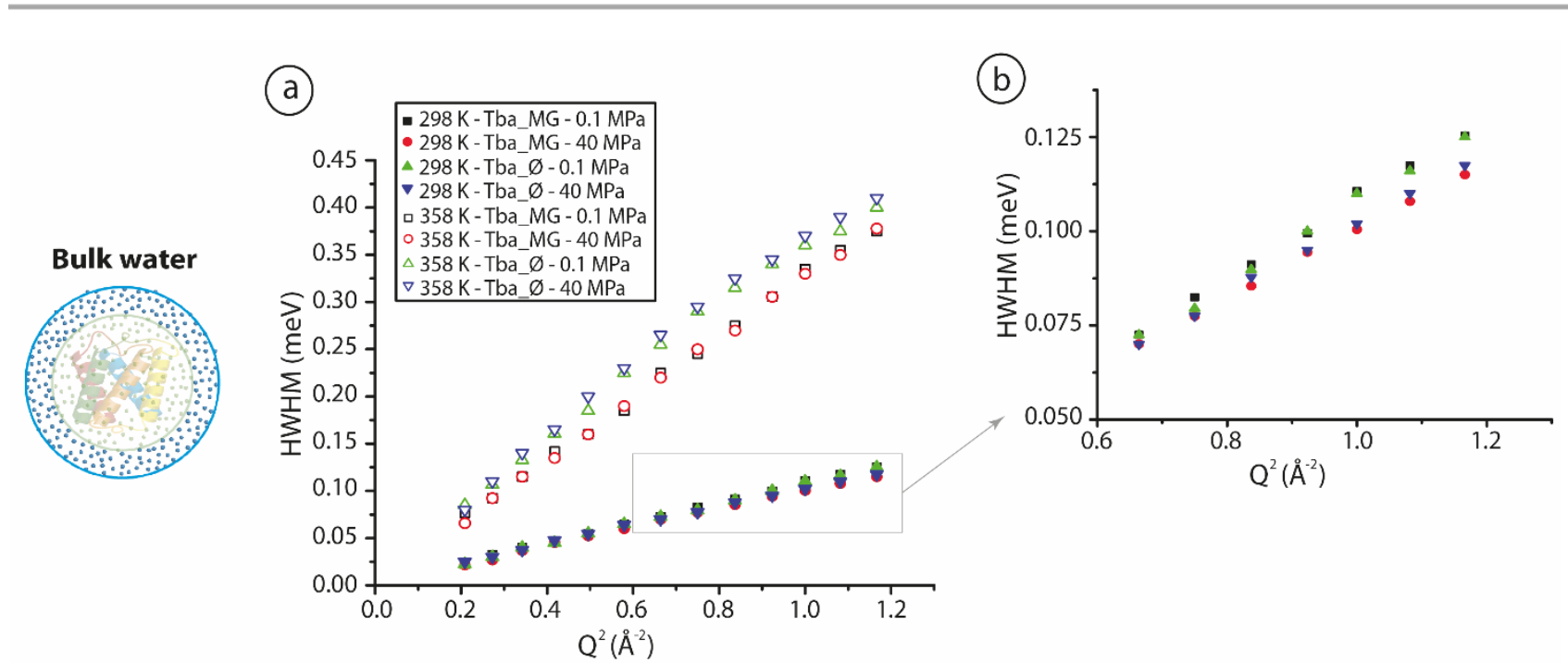

Figure 6. HWHM of the translational bulk water component (represented by blue dots in the left scheme) for both samples at different pressure ( $0.1 \mathrm{MPa}$ and $40 \mathrm{MPa}$ ) and temperature values ( $298 \mathrm{~K}$ and $358 \mathrm{~K}$ ) as a function of Q2. a) HWHM obtained at $298 \mathrm{~K}$ and $358 \mathrm{~K}$; b) zoom in on the $298 \mathrm{~K}$ region from $0.6 \AA-2<\mathrm{Q} 2<1.3 \AA$ - 2 . 
$\mathrm{meV})$ is of the same order that found before $(0.431 \pm 0.004$ meV) 10 and is specific for the $T$. barophilus proteome. The HWHM of the translational component for hydration and bulk water at the two temperatures studied ( $298 \mathrm{~K}$ and $358 \mathrm{~K}$ ) versus $\mathrm{Q}^{2}$ values are shown in Figure 5 and 6 . The curves present the typical signature for jump-diffusional motions ${ }^{34}$, e.g. they are almost linear in $\mathrm{Q}^{2}$, tending to zero at the origin and declining slightly at higher $Q$ values. As reported previously, the hydration water presents much slower motions than bulk water 54,55 . Focusing on the hydration water (Figure 5), one can observe that for both samples, the hydration water is less mobile at HHP ( $D_{\text {Thydration : }}(4.5 \pm 0.4) \cdot 10^{-7} \mathrm{~cm}^{2} \mathrm{~s}^{-1}$ vs. $(5.9 \pm 0.3) \cdot 10^{-7} \mathrm{~cm}^{2} \mathrm{~s}^{-1}$ and $(2.9 \pm 0.3) \cdot 10^{-7} \mathrm{~cm}^{2} \mathrm{~s}^{-1}$ vs. $(5.7 \pm 0.3) \cdot 10^{-7} \mathrm{~cm}^{2} \mathrm{~s}^{-1}$ for Tba_MG and Tba_ $\varnothing$, respectively). As expected, if MG is protecting the proteome and is therefore interacting with its hydration shell, this decrease in dynamics is more pronounced for the less crowded sample Tba_ $\varnothing$ (1.97 vs 1.31 times for Tba_ $\varnothing$ and Tba_MG, respectively). The translational diffusion coefficient for bulk water is the same for both samples and is essentially insensitive to HHP in the pressure range tested, but due to cell crowding, it is slightly inferior $\left(D_{\text {Tbulk }} \sim(1.85 \pm 0.05) \cdot 10^{-5} \mathrm{~cm}^{2} / \mathrm{s}\right)$ than that of free water at $298 \mathrm{~K}\left(D_{\text {Tfree }}=2.3 \cdot 10^{-5} \mathrm{~cm}^{2} / \mathrm{s}{ }^{56}\right)$. In contrast, the residence time, $\tau_{\text {Tbulk, }}$ which is related to interactions between molecules, and enhanced due to exchange mechanisms of biomolecules with hydration water, is pressure sensitive and increases with HHP. Such effect may be explained by a higher confinement due to HHP.

In summary, HHP does not have any impact on the population proportions in the sample or on the diffusion of bulk water $D_{\text {Tbulk. }}$ It slightly increases the residence time of bulk water $\boldsymbol{\tau}_{\text {Tbulk }}$ and decreases the diffusion coefficient of the hydration shell water $D_{\text {Thydration }}$ for both samples. The most important impact of pressure and crowding is on the diffusion coefficient of hydration water, $D_{\text {Thydration. }}$ Both, HHP and low crowding decrease $D_{\text {Thydration. }}$. The impact of HHP is more pronounced on $D_{\text {Thydration }}$ in the less crowded sample (Tba_ $\varnothing$ ) which confirms at the same time the pressure effect and the importance of crowding on cells.

The presence of the osmolyte MG is associated with a lowering of the impact of HHP on sample dynamics which translates into a lower decrease of the diffusion coefficient of the hydration shell water $D_{\text {Thydration. }}$. This data is congruent with the proposed mechanism of action for MG on protein stabilization 17,57,58.

Pressure and osmolyte accumulation effects on intracellular dynamics at $\mathbf{3 5 8} \mathrm{K}$. HT induces strong modifications of the relative contributions from the populations determined at 298 $\mathrm{K}$ (Table 1 ), which is characterized by an increase of $p_{\text {proteome }}$ concomitant with an increase in $p_{\text {hydration }}$ and a decrease of $p_{\text {bulk. }}$. HT mostly impacts the dynamics of the bulk water and proteome. The higher mobility of the proteome at higher temperatures is established by its higher $\Gamma_{\text {proteome }}=0.61 \pm 0.01$ $\mathrm{meV}$ at $358 \mathrm{~K}$ compared to $\Gamma_{\text {proteome }}=0.43 \pm 0.01 \mathrm{meV}$ at $298 \mathrm{~K}$. Bulk water dynamics (Figure 6) increases as a function of temperature $\left(D_{\text {Tbulk }}\right.$ varies from $\sim 1.85 \cdot 10^{-5} \mathrm{~cm}^{2} \mathrm{~s}^{-1}$ to $(5.2 \pm 0.1)$ and $(6.7 \pm 0.1) \cdot 10^{-5} \mathrm{~cm}^{2} \mathrm{~s}^{-1}$ for Tba_MG and Tba_ $\varnothing$, respectively).

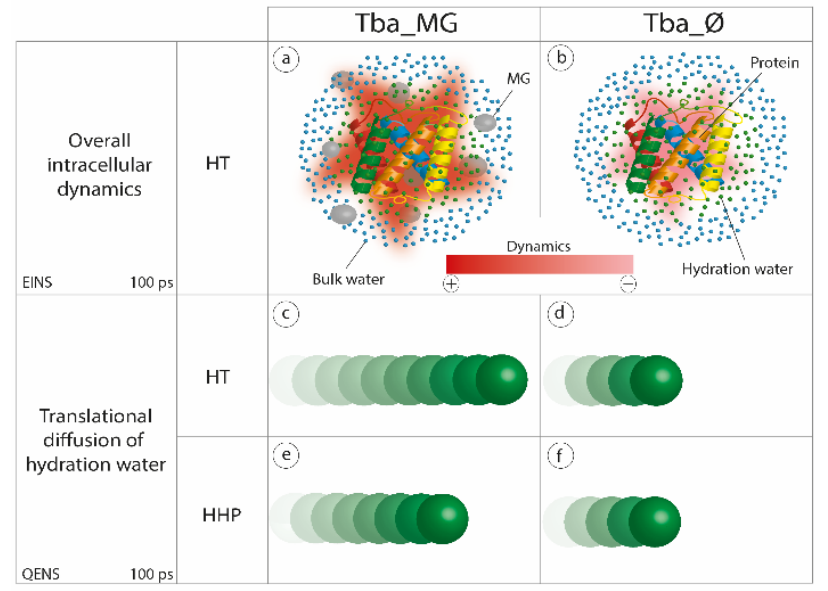

Figure 7. Schematic representation of main results for both samples at high-temperature $(\mathrm{HT}, 358 \mathrm{~K})$ and high hydrostatic pressure (HHP, $40 \mathrm{MPa})$. For clarity of presentation, this scheme intentionally simplifies the dynamics by neglecting the subdiffusive nature of hydration water. MG refers to mannosylglycerate. a) and b) represent the overall intracellular dynamics obtained by EINS at a time window of 100 ps: Tba_MG shows higher dynamics (dark red) than Tba_ $\varnothing$ at the same temperature (358 K). From c) to f): representation of translational diffusion of hydration water for both samples at HT and HHP obtained by QENS for a time window of 100 ps, more "green dots" represents higher dynamics. Tba_ $\varnothing$ manifests lower dynamics of hydration water than Tba_MG at HT (c,d), but also at $\operatorname{HHP}(\mathrm{e}, \mathrm{f})$.

The translational bulk water component is not pressure sensitive for the pressure range studied. As observed for $D_{\text {Tbulk }}$ at $298 \mathrm{~K}$, it is slower than free water at the corresponding temperature $\left(D_{\text {Tfree }}=7.3 \cdot 10^{-5} \mathrm{~cm}^{2} / \mathrm{s}\right.$ at $\left.358 \mathrm{~K}^{59}\right)$. The presence of osmolytes in sample Tba_MG is associated with a lower increase of bulk water dynamics (Figure 6a) and slower motions $\left(D_{\text {Tbulk }}=(5.2 \pm 0.1) \cdot 10^{-5} \mathrm{~cm}^{2} / \mathrm{s}\right)$ in contrast to the sample without osmolytes, Tba_ $\varnothing\left(D_{\text {Tbulk }}=(6.7 \pm 0.1) \cdot 10^{-5} \mathrm{~cm}^{2} / \mathrm{s}\right)$, which further confirms that crowding impacts bulk water motions, as reported previously for lysed cells ${ }^{35}$. This impact of osmolyte crowding on bulk waters dynamics should be visible at $298 \mathrm{~K}$, but is too small to be quantified accurately (Figure 6b).

As observed at low temperature, the translational diffusion coefficient of hydration water ( $D_{\text {Thydration }}$ ) decreases with HHP by a factor of ca. 1.5. Moreover, the less crowded sample, Tba_ $\varnothing$, presents lower dynamics than Tba_MG at room pressure $\left(D_{\text {Thydration }}=(2.7 \pm 0.4) \cdot 10^{-7} \mathrm{~cm}^{2} / \mathrm{s} \mathrm{vs} .(5.6 \pm 0.4) \cdot 10^{-7} \mathrm{~cm}^{2} / \mathrm{s}\right)$, which is congruent with previous reports that less crowded samples present lower $D_{\text {Thydration }}{ }^{35}$.

In summary, HT changes the contributions of the different populations detected, it increases the dynamics and the ratio of $p_{\text {proteome, }}$ which is accompanied by an increase of $p_{\text {hydration }}$ and a consequent decrease of $p_{\text {bulk. }}$. Temperature increases dynamics as observed for $D_{\text {Tbulk, }}$, and, furthermore, Tba_ $\varnothing$ presents higher translational diffusion of bulk water, which is congruent with a lower crowding of the cells. However, temperature does not increase $D_{\text {Thydration: }}$ Indeed, Tba_ $\varnothing$ shows lower $D_{\text {Thydration }}$ at 358 $\mathrm{K}$ than at $298 \mathrm{~K}$.

\section{Conclusions}

Taken together the QENS and EINS results demonstrate that Tba_ $\varnothing$ displays lower dynamics than Tba_MG at HT and HHP 
(Figure 7). Macromolecular components, such as lipids or nucleic acids, could affect cell dynamics. However, due to their low concentration in the cells, e.g. ca. $10 \%$ for lipids and $20 \%$ for RNAs for example, their contribution to the QENS and EINS signal, which averages the whole cell, is only marginal. Since, the significative QENS and EINS signal originates solely from proteins, which constitute more than $50 \%$ of the cell macromolecules, the lower dynamics most probably originates from the proteome reorganization as seen on the EINS data (Figure 2). The Tba_ $\varnothing D_{\text {Thydration }}$ value at its optimal pressure (40 $\mathrm{MPa})$ and temperature $(358 \mathrm{~K})$, i.e. $(1.8 \pm 0.4) \cdot 10^{-7} \mathrm{~cm}^{2} / \mathrm{s}$, is very similar to that found for hydration water on other cell types at their own optimal temperatures. For example, at $310 \mathrm{~K}$, red blood cells present a diffusion coefficient of $\sim 1.75 \cdot 10^{-7} \mathrm{~cm}^{2} / \mathrm{s}$ 60 , E. coli at $303 \mathrm{~K}$ has a $D_{\text {Thydration }} \sim 1.1 \cdot 10^{-7} \mathrm{~cm}^{2} / \mathrm{s}^{29}$ and $H$. marismortui presents a $D_{\text {Thydration }} \sim 1 \cdot 10^{-7} \mathrm{~cm}^{2} / \mathrm{s}$ at $300 \mathrm{~K}{ }^{30}$. These values indicate that regardless the cell type or their optimal growth temperature, the cell dynamics required to maintain the macromolecules functional implies that the hydration water dynamics is of the same order. This resembles the "corresponding state principle" 8,9 which states that the flexibility of proteins adapted to extreme conditions should be of the same magnitude than a non-extremophile protein at ambient conditions. It is striking that the possible rearrangements of the $T$. barophilus proteome occurs at the lowest temperature permissive for growth, much like it was shown to occur at the lowest hydrostatic pressure which did not include a stress on cells ${ }^{52}$. Thus, the lower $D_{\text {Thydration }}$ found in Tba_ $\varnothing$ may reflect the structural adaptation of the $T$. barophilus proteome to HT as observed by EINS.

Mannosylglycerate is the osmolyte accumulated under hydrostatic pressure stress in T. barophilus, i.e. at ambient pressure. Sample Tba_ $\varnothing$, which is less crowded in absence of the osmolyte MG, presents some characteristics similar to that found in lysed cells, where crowding effect is highly diminished: 1 ) at $298 \mathrm{~K}$, Tba_ $\varnothing$ has a more pressure-sensitive dynamics since the decrease on hydration diffusion is stronger; 2) at $358 \mathrm{~K}$, Tba_ $\varnothing$ displays the higher translational diffusion for bulk water; 3 ) at highest temperature, Tba_ $\varnothing$ presents lower translational diffusion at both pressures studied.

In the present investigation, we have studied intact, live cells, which indicates that the accumulation of osmolytes as a response to pressure stress significantly impacts the intracellular crowding. It has been proposed to act by rigidifying the protein structure, although the exact mechanism was not fully detailed 57 . All our results are congruent with this hypothesis, and further support that MG does not influence protein dynamics directly, but through a crowding effect, possibly at the hydration shell level.

Our data on the $T$. barophilus proteome clearly demonstrates the existence of a pressure induced phase transition, from the low pressure, highly flexible and probably non-functional state, to a drastically less flexible, and biologically functional one at 400 bars. Until recently, there was no clear explanation for such an observation, since it is expected that increasing hydrostatic pressure will destabilize the structural organization of proteins. A similar behaviour has been observed in the g-D-crystallin 61
Indeed, under its physiological conditions, this protein is properly folded and appears transparent which is consistent with its biological function in the eye lens. At lower temperature, the protein in solution appears turbid, and the proper folding is induced by increasing hydrostatic pressure. Thus, as we observe in the $T$. barophilus proteome, pressure seems to induce a transition from a poorly folded, non functional state to a properly folded, functional one. In the case of $T$. barophilus, the functional, e.g. normal state, is 400 bars and $85^{\circ} \mathrm{C}$, thus functionally, the lowering of pressure is inducing the transition to the poorly folded state. In $\gamma$-D-crystallin, this pressure-induced folding has been explained in part by more configurational freedom, less void volume and far fewer hydrophobic contacts, but interactions of all types may also contribute to this transition ${ }^{62}$. Although our data does not allow us to identify the cause of the phase transition observed in $T$. barophilus, we believe that they are the similar to those explaining the phase transition in $\gamma$-D-crystallin.

Our observation of the pressure sensitivity of the $T$. barophilus proteome in a very narrow pressure range is a new example in the now longer list of proteins sensitive to very small variations of hydrostatic pressure, e.g. $\gamma$-D-crystallin, lysozyme, $\alpha$-elastin and Deadbox helicase ${ }^{62}$, which undergo pressure-sensitive liquid-liquid phase separation (LLPS). These findings are of paramount importance for our studies, although the relation between LLPS and molecular dynamics of proteins within cells is not yet established and has to be further investigated. However, the pressure sensitivity of $T$. barophilus is observed within a few tens to hundreds of bar and is altered by the presence of the osmolyte MG. Regardless of the underlying mechanism, what the different systems tell us is that what drives the biological function is the corresponding principle ${ }^{8}$, which states that the physiologically relevant value a specific parameter can take belongs to a very narrow range of values, independently of the environmental conditions. For example, the flexibility of a functional protein/proteome will be similar in T. barophilus at 400 bars and $85^{\circ} \mathrm{C}$, and in $\gamma$-D-crystallin at ambient pressure and $37^{\circ} \mathrm{C}$. Any variation from these values, will lead to the destabilization of the proteic structure. Under moderate pressure stress, osmolytes can protect proteins against unfolding. In T. barophilus, MG is expected to interact strongly with the hydration shell water, which can be seen by enhanced translational diffusion coefficients of hydration water, which is different from what has been characterized for the well studied osmolyte TMAO, which is excluded from the hydration shell. It would therefore be interesting to investigate how MG induces such behaviour at the protein surface or in hydration water.

This work further extends on previous observations that the main HHP adaptive mechanisms of piezophiles include specific populations' ratios and a decrease in hydration water diffusion. Such pressure-response is higher at Tba_ $\varnothing$, in absence of MG. Moreover, at both HHP response studies at $298 \mathrm{~K}$, we could detect a higher residence time of bulk water and therefore, a higher confinement due to the increase of pressure. Further 
work on the basis for the pressure sensitivity of proteins will help in the identification of the structural adaptations required in piezophilic enzymes for life at HHP.

\section{Conflicts of interest}

There are no conflicts to declare.

\section{Acknowledgements}

We are gratefully acknowledging the ILL for allocation of beam time and the CNRS - Défi Instrumentation aux Limites 2014 for financing the development of the high-pressure cell. We would like to thank the two anonymous reviewers whose comments helped us improve the quality of this manuscript.

\section{References}

(1) Brock, T. D.; Brock, K. M.; Belly, R. T.; Weiss, R. L. Sulfolobus: A New Genus of Sulfur-Oxidizing Bacteria Living at Low PH and High Temperature. Arch. Mikrobiol. 1972, 84 (1), 54-68. https://doi.org/10.1007/BF00408082.

(2) Yayanos, A. A.; Dietz, A. S.; Van Boxtel, R. Isolation of a Deep-Sea Barophilic Bacterium and Some of Its Growth Characteristics. Science (80-. ). 1979, 205 (4408), 808-810. https://doi.org/10.1126/science.205.4408.808.

(3) Pikuta, E. V.; Hoover, R. B.; Tang, J. Microbial Extremophiles at the Limits of Life. Crit. Rev. Microbiol. 2007, 33 (3), 183-209. https://doi.org/10.1080/10408410701451948. Campanaro, S.; Vezzi, A.; Vitulo, N.; Lauro, F. M.; D’Angelo, M.; Simonato, F.; Cestaro, A.; Malacrida, G.; Bertoloni, G.; Valle, G.; et al. Laterally Transferred Elements and High Pressure Adaptation in Photobacterium Profundum Strains. BMC Genomics 2005, 6, 1-15.

https://doi.org/10.1186/1471-2164-6-122.

(5) Oger, P. M.; Jebbar, M. The Many Ways of Coping with Pressure. Res. Microbiol. 2010, 161 (10), 799-809. https://doi.org/10.1016/j.resmic.2010.09.017.

(6) Oger, P. M.; Cario, A. Adaptation of the Membrane in Archaea. Biophys. Chem. 2013, 183, 42-56. https://doi.org/10.1016/j.bpc.2013.06.020.

(7) Brininger, C.; Spradlin, S.; Cobani, L.; Evilia, C. The More Adaptive to Change, the More Likely You Are to Survive: Protein Adaptation in Extremophiles. Semin. Cell Dev. Biol. 2018, 84, 158-169.

https://doi.org/10.1016/j.semcdb.2017.12.016.

(8) Vihinen, M. Relationship of Protein Flexibility to Thermostability. Protein Eng. 1987, 1 (6), 477-480. https://doi.org/10.1093/protein/1.6.477.

(9) Jaenicke, R. Stability and Stabilization of Globular Proteins in Solution. J. Biotechnol. 2000, 79 (3), 193-203. https://doi.org/10.1016/S0168-1656(00)00236-4.

(10) Martinez, N.; Michoud, G.; Cario, A.; Ollivier, J.; Franzetti, B.; Jebbar, M.; Oger, P.; Peters, J. High Protein Flexibility and Reduced Hydration Water Dynamics Are Key Pressure Adaptive Strategies in Prokaryotes. Sci. Rep. 2016, 6 (April), 1-11. https://doi.org/10.1038/srep32816.

(11) Le Chatelier, H. L. Sur Un Enoncé Général Des Lois Des Équilibres Chimiques. Comptes-rendus de l'Académie des sciences. 1884, pp 786-789.

Cario, A.; Jebbar, M.; Thiel, A.; Kervarec, N.; Oger, P. M. Molecular Chaperone Accumulation as a Function of Stress Evidences Adaptation to High Hydrostatic Pressure in the Piezophilic Archaeon Thermococcus Barophilus. Sci. Rep. 2016, 6 (July), 1-8. https://doi.org/10.1038/srep29483.

(13) Gao, M.; Held, C.; Patra, S.; Arns, L.; Sadowski, G.; Winter, R. Crowders and Cosolvents-Major Contributors to the Cellular Milieu and Efficient Means to Counteract Environmental Stresses. ChemPhysChem 2017, 18 (21), 2951-2972. https://doi.org/10.1002/cphc.201700762.

(14) Wood, J. M.; Bremer, E.; Csonka, L. N.; Kraemer, R.; Poolman, B.; Van der Heide, T.; Smith, L. T. Osmosensing and Osmoregulatory Compatible Solute Accumulation by Bacteria. Comp. Biochem. Physiol. - A Mol. Integr. Physiol. 2001, 130 (3), 437-460. https://doi.org/10.1016/S10956433(01)00442-1.

(15) Empadinhas, N.; Da Costa, M. S. Diversity and Biosynthesis of Compatible Solutes in Hyper/Thermophiles. Int. Microbiol. 2006, 9 (3), 199-206.

(16) Al-Ayoubi, S. R.; Schummel, P. H.; Golub, M.; Peters, J.; Winter, R. Influence of Cosolvents, Self-Crowding, Temperature and Pressure on the Sub-Nanosecond Dynamics and Folding Stability of Lysozyme. Phys. Chem. Chem. Phys. 2017, 19 (22), 14230-14237. https://doi.org/10.1039/c7cp00705a.

(17) Borges, N.; Ramos, A.; Raven, N.; Sharp, R.; Santos, H. Comparative Study of the Thermostabilizing Properties of Mannosylglycerate and Other Compatible Solutes on Model Enzymes. Extremophiles 2002, 6, 209-216. https://doi.org/10.1007/s007920100236.

Balny, C.; Masson, P.; Heremans, K. High Pressure Effects on Biological Macromolecules: From Structural Changes to Alteration of Cellular Processes. Biochim. Biophys. Acta Protein Struct. Mol. Enzymol. 2002, 1595 (1-2), 3-10. https://doi.org/10.1016/S0167-4838(01)00331-4. Martin, D. D.; Bartlett, D. H.; Roberts, M. F. Solute Accumulation in the Deep-Sea Bacterium Photobacterium Profundum. Extremophiles 2002, 6 (6), 507-514. https://doi.org/10.1007/s00792-002-0288-1.

(20) Fitter, J.; Lechner, R. E.; Buldt, G.; Dencher, N. A. Internal Molecular Motions of Bacteriorhodopsin: HydrationInduced Flexibility Studied by Quasielastic Incoherent Neutron Scattering Using Oriented Purple Membranes. Proc. Natl. Acad. Sci. 1996, 93, 7600-7605. https://doi.org/10.1073/pnas.93.15.7600. García Sakai, V.; Arbe, A. Current Opinion in Colloid \& Interface Science Quasielastic Neutron Scattering in Soft Matter. Curr. Opin. Colloid Interface Sci. 2009, 14 (6), 381390. https://doi.org/10.1016/j.cocis.2009.04.002. Influence of Ions on Water Diffusion - A Neutron Scattering 
Study. J. Phys. Chem. B 2013, 117 (25), 7724-7728. https://doi.org/10.1021/jp4030415.

(23) Stadler, A. M.; Koza, M. M.; Fitter, J. Determination of Conformational Entropy of Fully and Partially Folded Conformations of Holo- and Apomyoglobin. J. Phys. Chem. B 2014, 119, 72-82. https://doi.org/10.1021/jp509732q.

(24) Grimaldo, M.; Roosen-runge, F.; Hennig, M.; Zanini, F. Hierarchical Molecular Dynamics of Bovine Serum and above Thermal Denaturation †. Phys. Chem. Chem. Phys. 2015, 17, 4645-4655. https://doi.org/10.1039/c4cp04944f. Erlkamp, M.; Marion, J.; Martinez, N.; Czeslik, C.; Peters, J.; Winter, R. Influence of Pressure and Crowding on the SubNanosecond Dynamics of Globular Proteins. J. Phys. Chem. B 2015, 119 (14), 4842-4848.

https://doi.org/10.1021/acs.jpcb.5b01017.

(26) Ellis, R. J. Macromolecular Crowding: An Important but Neglected Aspect of the Intracellular Environment. Curr. Opin. Struct. Biol. 2011, 11, 114-119.

https://doi.org/10.1016/S0959-440X(00)00172-X.

Luong, T. Q.; Kapoor, S.; Winter, R. Pressure - A Gateway to Fundamental Insights into Protein Solvation, Dynamics, and Function. ChemPhysChem 2015, 16 (17), 3555-3571. https://doi.org/10.1002/cphc.201500669.

(28) Tehei, M.; Franzetti, B.; Madern, D.; Ginzburg, M.; Ginzburg, B. Z.; Giudici-Orticoni, M.-T.; Bruschi, M.; Zaccai, G. Adaptation to Extreme Environments: Macromolecular Dynamics in Bacteria Compared in Vivo by Neutron Scattering. EMBO Rep. 2004, 5 (1), 66-70. https://doi.org/10.1038/sj.embor.7400049.

(29) Jasnin, M.; Moulin, M.; Haertlein, M.; Zaccai, G.; Tehei, M. In Vivo Measurement of Internal and Global

Macromolecular Motions in Escherichia Coli. Biophys. J. 2008, 95 (2), 857-864.

https://doi.org/10.1529/biophysj.107.124420.

(30) Tehei, M.; Franzetti, B.; Wood, K.; Gabel, F.; Fabiani, E.; Jasnin, M.; Zamponi, M.; Oesterhelt, D.; Zaccai, G.; Ginzburg, M.; et al. Neutron Scattering Reveals Extremely Slow Cell Water in a Dead Sea Organism. Proc. Natl. Acad. Sci. U. S. A. 2007, 104 (3), 766-771. https://doi.org/10.1073/pnas.0601639104

(31) Marty, V.; Jasnin, M.; Fabiani, E.; Vauclare, P.; Gabel, F.; Trapp, M.; Peters, J.; Zaccai, G.; Franzetti, B. Neutron Scattering: A Tool to Detect in Vivo Thermal Stress Effects at the Molecular Dynamics Level in Micro-Organisms. J. $R$. Soc. Interface 2013, 10 (82), 1-6. https://doi.org/10.1098/rsif.2013.0003.

(32) Vauclare, P.; Marty, V.; Fabiani, E.; Martinez, N.; Jasnin, M.; Gabel, F.; Peters, J.; Zaccai, G.; Franzetti, B. Molecular Adaptation and Salt Stress Response of Halobacterium Salinarum Cells Revealed by Neutron Spectroscopy. Extremophiles 2015, 19 (6), 1099-1107. https://doi.org/10.1007/s00792-015-0782-x.

(33) Foglia, F.; Hazael, R.; Simeoni, G. G.; Appavou, M.-S. Moulin, M.; Haertlein, M.; Trevor Forsyth, V.; Seydel, T.; Daniel, I.; Meersman, F.; et al. Water Dynamics in Shewanella Oneidensis at Ambient and High Pressure Using Quasi-Elastic Neutron Scattering. Sci. Rep. 2016, 6 (1), 1-9. https://doi.org/10.1038/srep18862.

(34) Bée, M. QuasiElastic Neutron Scattering: Principles and Applications in Solid State Chemistry, Biology and Materials Scien; Adam Hilger, 1988.

(35) Golub, M.; Martinez, N.; Peters, J.; Michoud, G.; Ollivier, J.; Jebbar, M.; Oger, P. The Effect of Crowding on Protein Stability, Rigidity, and High Pressure Sensitivity in Whole Cells. Langmuir 2018, 34 (35), 10419-10425. https://doi.org/10.1021/acs.langmuir.8b01240.

Zeng, X.; Birrien, J. L.; Fouquet, Y.; Cherkashov, G.; Jebbar, M.; Querellou, J.; Oger, P.; Cambon-Bonavita, M. A.; Xiao, X.; Prieur, D. Pyrococcus $\mathrm{CH} 1$, an Obligate Piezophilic Hyperthermophile: Extending the Upper PressureTemperature Limits for Life. ISME J. 2009, 3 (7), 873-876. https://doi.org/10.1038/ismej.2009.21

(37) Cario, A.; Grossi, V.; Schaeffer, P.; Oger, P. M. Membrane Homeoviscous Adaptation in the Piezo-Hyperthermophilic Archaeon Thermococcus Barophilus. Front. Microbiol.

2015, 6 (OCT), 1-12. https://doi.org/10.3389/fmicb.2015.01152.

(38) Peters, J.; Golub, M.; Demé, B.; Gonthier, J.; Maurice, J.; Payre, C.; Sadykov, R.; Lelièvre-Berna, E. New Pressure Cells for Membrane Layers and Systems in Solutions up to $100^{\circ} \mathrm{C}$. J. Neutron Res. 2018, 20 (1-2), 1-10. https://doi.org/10.3233/JNR-180055.

(39) Sidorov, V. A.; Sadykov, R. A. Hydrostatic Limits of Fluorinert Liquids Used for Neutron and Transport Studies at High Pressure. J. Phys. Condens. Matter 2005, 17 (40), 37. https://doi.org/10.1088/0953-8984/17/40/002.

(40) Lelièvre-Berna, E.; Demé, B.; Gonthier, J.; Gonzales, J. P.; Maurice, J.; Memphis, Y.; Payre, C.; Oger, P.; Peters, J.; Vial, S. $700 \mathrm{MPa}$ Sample Stick for Studying Liquid Samples or Solid-Gas Reactions down to $1.8 \mathrm{~K}$ and up to $550 \mathrm{~K}$. J. Neutron Res. 2017, 19 (1-2), 77-84. https://doi.org/10.3233/JNR-170044.

(41) Sears, V. F. Neutron Scattering Lengths and Cross Sections. Neutron News 1992, 3 (3), 26-37. https://doi.org/10.1080/10448639208218770. Francesca, N.; Peters, J.; Russo, D.; Barbieri, S.; Chiapponi, C.; Cupane, A.; Deriu, A.; Di Bari, M. T.; Farhi, E.; Gerelli, Y.; et al. IN13 Backscattering Spectrometer at ILL: Looking for Motions in Biological Macromolecules and Organisms. Neutron News 2008, 19 (4), 14-18. https://doi.org/10.1080/10448630802474083.

Disk chopper time-of-flight spectrometer IN5 https://www.ill.eu/users/instruments/instrumentslist/in5/description/instrument-layout/ (accessed Feb 27, 2019).

(44) Richard, D.; Ferrand, M.; Kearley, G. J. Analysis and Visualisation of Neutron-Scattering Data. J. Neutron Res. 1996, 4 (1-4), 33-39. https://doi.org/10.1080/10238169608200065.

(45) Trapp, M.; Marion, J.; Tehei, M.; Demé, B.; Gutberlet, T.; Peters, J. High Hydrostatic Pressure Effects Investigated by Neutron Scattering on Lipid Multilamellar Vesicles. Phys. Chem. Chem. Phys. 2013, 15 (48), 20951-20956. https://doi.org/10.1039/c3cp52762j. 
(46) Busch, S.; Unruh, T. The Slow Short-Time Motions of Phospholipid Molecules with a Focus on the Influence of Multiple Scattering and Fitting Artefacts. J. Phys. Condens. Matter 2011, 23 (25). https://doi.org/10.1088/09538984/23/25/254205.

(47) Rahman, A.; Singwi, K. S.; Sjölander, A. Theory of Slow Neutron Scattering by Liquids. I. Phys. Rev. 1962, 126 (3), 986-996. https://doi.org/10.1103/PhysRev.126.986.

(48) Smith, J. C. Protein Dynamics: Comparison of Simulations with Inelastic Neutron Scattering Experiments. Q. Rev. Biophys. 1991, 24 (3), 227-291. https://doi.org/10.1017/S0033583500003723.

(49) Paciaroni, A.; Casciola, M.; Cornicchi, E.; Marconi, M.; Onori, G.; Pica, M.; Narducci, R. Temperature-Dependent Dynamics of Water Confined in Nafion Membranes. J. Phys. Chem. B 2006, 110 (28), 13769-13776.

https://doi.org/10.1021/jp0572176.

(50) Gerelli, Y.; Sakai, V. G.; Ollivier, J.; Deriu, A. Conformational and Segmental Dynamics in Lipid-Based Vesicles. Soft Matter 2011, 7 (8), 3929-3935. https://doi.org/10.1039/c0sm01301c.

(51) Bratbak, G. Bacterial Biovolume and Biomass Estimations. Appl. Environ. Microbiol. 1985, 49 (6), 1488-1493.

(52) Peters, J.; Martinez, N.; Michoud, G.; Cario, A.; Franzetti, B.; Oger, P.; Jebbar, M. Deep Sea Microbes Probed by Incoherent Neutron Scattering under High Hydrostatic Pressure. Zeitschrift fur Phys. Chemie 2014, 228 (10-12), 1121-1133. https://doi.org/10.1515/zpch-2014-0547.

(53) Marteinsson, V. T.; Birrien, J.-L.; Reysenbach, A.; Vernet, M.; Marie, D.; Gambacorta, A.; Messner, P.; Sleytr, U. B.; Prieur, D. Thermococcus Barophilus Sp. Nov., a New Barophilic and Hyperthermophilic Archaeon Isolated under High Hydrostatic Pressure from a Deep-Sea Hydrothermal Vent. Int. J. Syst. Bacteriol. 1999, 49, 351-359.

(54) Settles, M.; Doster, W. Anomalous Diffusion of Adsorbed Water: A Neutron Scattering Study of Hydrated Myoglobin. Faraday Discuss. 1996, 103, 269-279. https://doi.org/10.1039/fd9960300269.

(55) Dellerue, S. Relaxational Dynamics of Water Molecules at Protein Surface. Chem. Phys. 2000, 258 (2-3), 315-325. https://doi.org/10.1016/S0301-0104(00)00181-6.

(56) Teixeira, J.; Bellissent-Funel, M. C.; Chen, S. H.; Dianoux, A. J. Experimental Determination of the Nature of Diffusive Motions of Water Molecules at Low Temperatures. Phys. Rev. A 1985, 31 (3), 1913-1917. https://doi.org/10.1103/PhysRevA.31.1913.

(57) Faria, T. Q.; Knapp, S.; Ladenstein, R.; Maçanita, A. L.; Santos, H. Protein Stabilisation by Compatible Solutes: Effect of Mannosylglycerate on Unfolding Thermodynamics and Activity of Ribonuclease A. ChemBioChem 2003, 4 (8), 734-741. https://doi.org/10.1002/cbic.200300574.

(58) Faria, T. Q.; Lima, J. C.; Bastos, M.; Maçanita, A. L.; Santos, H. Protein Stabilization by Osmolytes from Hyperthermophiles. J. Biol. Chem. 2004, 279 (47), 4868048691. https://doi.org/10.1074/jbc.m408806200.

(59) Simpson, J. H.; Carr, H. Y. Diffusion and Nuclear Spin Relaxation in Water. Phys. Rev. 1958, 111 (5), 1201-1202.
(60) Doster, W.; Longeville, S. Microscopic Diffusion and Hydrodynamic Interactions of Hemoglobin in Red Blood Cells. Biophys. J. 2007, 93 (4), 1360-1368. https://doi.org/10.1529/biophysj.106.097956.

(61) Cinar, S.; Cinar, H.; Chan, H. S.; Winter, R. PressureSensitive and Osmolyte-Modulated Liquid-Liquid Phase Separation of Eye-Lens $\mathrm{\gamma}$-Crystallins. J. Am. Chem. Soc. 2019, 141 (18), 7347-7354. https://doi.org/10.1021/jacs.8b13636.

(62) Cinar, H.; Fetahaj, Z.; Cinar, S.; Vernon, R. M.; Chan, H. S.; Winter, R. H. A. Temperature, Hydrostatic Pressure, and Osmolyte Effects on Liquid-Liquid Phase Separation in Protein Condensates: Physical Chemistry and Biological Implications. Chem. - A Eur. J. 2019, chem.201902210. https://doi.org/10.1002/chem.201902210. 